\title{
Synthesis and properties of Oxasmaragdyrins containing one Five-membered Heterocycle at Meso-position
}

\author{
BOORUGA UMASEKHAR, PALLAB SAMANTA, TAMAL CHATTERJEE and \\ MANGALAMPALLI RAVIKANTH* \\ Department of Chemistry, Indian Institute of Technology Bombay, Mumbai, Maharashtra 400 076, India \\ e-mail: ravikanth@chem.iitb.ac.in
}

MS received 9 August 2016; revised 5 September 2016; accepted 7 September 2016

\begin{abstract}
The oxasmaragdyrins containing one five membered heterocycle such as pyrrole, thiophene and furan in place of one of the meso-phenyl group were synthesized by acid-catalyzed oxidative coupling reaction of meso-heterocycle substituted dipyrromethane with 16-oxatripyrrane in the presence of catalytic amount of trifluoroacetic acid followed by oxidation with DDQ. The smaragdyrin macrocycles containing one fivemembered heterocycle at meso-position were characterized by HR-MS and detailed 1D and 2D NMR studies. The absorption and fluorescence studies revealed that the presence of five membered heterocycle at mesoposition of smaragdyrin resulted in bathochromic shifts in absorption and emission bands with slight reduction in quantum yields compared to smraragdyrin macrocycle containing six membered meso-phenyl groups. The electrochemical studies revealed that the meso-heterocycle smaragdyrins are electron deficient compared to meso-phenyl smaragdyrins.
\end{abstract}

Keywords. Expanded porphyrin; smaragdyrin; heterocycle; fluorescence; redox potentials.

\section{Introduction}

Smaragdyrins are $22-\pi$ aromatic pentapyrrolic macrocycles in which five pyrrole rings are connected via three meso-carbons and two direct pyrrole-pyrrole bonds. ${ }^{1}$ Smaragdyrins are intense green coloured solids and first discovered by R. B. Woodward during his pioneering synthesis of Vitamin $\mathrm{B}_{12} \cdot{ }^{2 \mathrm{a}}$ However, the first synthesis of smaragdyrins was reported by Grigg, Johnson and co-workers which they named as "norsapphyrins'. ${ }^{2 b}$ At the same time, Woodward group also discovered another pentapyrrolic macrocycle called sapphyrin which contains four meso-carbons and one direct pyrrole-pyrrole bond. ${ }^{3}$ The chemistry of sapphyrins developed significantly over the years after the initial serendipitous discovery of their anion sensing behaviour by Sessler and co-workers. ${ }^{4}$ Interestingly, unlike sapphyrin, the chemistry of smaragdyrin is not well-developed until recently due to their inherent unstable nature because of the presence of two direct pyrrole-pyrrole bonds which induces the strain in the macrocycle that lead to the decomposition. However,

\footnotetext{
*For correspondence

Dedicated to Professor Tavarekere K Chandrashekar on the occasion of his $60^{\text {th }}$ birth anniversary
}

Chandrashekar group reported the synthesis of stable meso-triaryl smaragdyrin by substituting one pyrrole ring with furan ring. ${ }^{5}$ The resulted smaragdyrins known as meso-aryl oxasmaragdyrins are stable and exhibit novel spectral and electrochemical properties. The oxasmaragdyrins exhibit absorption and emission bands in 400-800 nm region with decent quantum yields and singlet state lifetimes, and are stable under redox conditions. Smaragdyrins are also known to form metal/nonmetal complexes and also show anion binding ability. ${ }^{6-8}$ However, most of the oxasmaragdyrins known till date contain only six-membered aryl groups at the mesopositions. It is advantageous to have one five-membered heterocycle such as pyrrole, thiophene or furan at the meso position which not only significantly alters the electronic properties of the macrocycle but also the meso-heterocyclic group can be easily functionalized to extend the chemistry. With this idea in the mind, here we report the synthesis of mono mesoheterocycle containing oxasmaragdyrins 2-4 and compare their spectral and electrochemical properties with meso-triaryl smaragdyrin 1 (Chart 1). The presence of one five-membered heterocycle at meso-position significantly alters the electronic properties of smaragdyrin macrocycle as reflected in their spectral and electrochemical properties. 


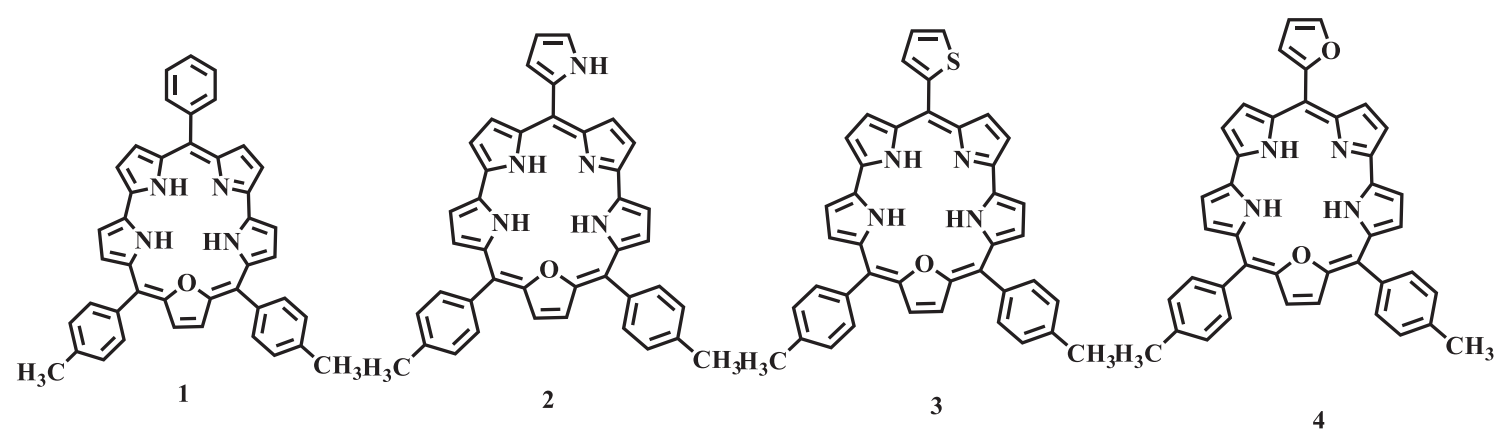

Chart 1. Molecular structures of different oxasmaragdyrins 1-4.

\section{Experimental}

\subsection{Chemicals}

All the chemicals such as pyrrole and 2,3-dichloro5,6-dicyano-1,4-benzoquinone (DDQ) were used as obtained from Aldrich. All other chemicals used for the synthesis were reagent grade. The solvents like dichloromethane, $n$-hexane and chloroform were purified and distilled by standard procedures before use. Silica gel and basic alumina used for column chromatography have been obtained from Sisco Research Laboratories, India. Tetrabutylammonium perchlorate was purchased from Fluka. All NMR solvents were bought from Aldrich. The known compounds such as 5,10- di-( $p$-tolyl)-tripyrromethane ${ }^{9} \mathbf{5}$ and $2,2^{\prime}-(1-$ pyrroyl/thienyl/furylethylidene)bis-Pyrrole ${ }^{10}$ 6-8 were synthesized by following the literature methods.

\subsection{Instrumentation}

The ${ }^{1} \mathrm{H}$ and ${ }^{13} \mathrm{C}$ NMR ( $\delta$ in parts per million) spectra were recorded by using a Bruker AVANCE III $400 \mathrm{MHz}$ and $500 \mathrm{MHz}$ spectrometer. Tetramethylsilane (TMS) was used as an internal reference for recording ${ }^{1} \mathrm{H}$ NMR spectra (residual proton; $\delta=7.26 \mathrm{ppm}$ ) in $\mathrm{CDCl}_{3}$. The HR-MS spectra were recorded by Q-Tof micromass spectrometer working based on electrospray ionization method. The absorption and steady state flouroscence spectra were obtained with Jasco V-670 spectrometer and HoribaJobin Yvon Nanolog UV-visible-NIR spectrofluorimeter, respectively, and quantum yields were estimated at $420 \mathrm{~nm}$ by comparative method using meso-tetraphenylporphyrin $\left(\mathrm{H}_{2} \mathrm{TPP}\right)$ as standard $\left(\Phi_{\mathrm{f}}\right)$. Cyclic voltammetry (CV) experiments were carried out in a BAS electrochemical system, by using glassy carbon as working electrode, platinum wire as auxiliary electrode and saturated calomel as reference electrodes.

\subsection{General synthesis of compounds 2-4}

The acid-catalyzed oxidative coupling reaction of tripyrromethane $\mathbf{5}$ (1 $\mathrm{mmol})$ and appropriate dipyrromethane $\mathbf{6 / 7 / 8}(1 \mathrm{mmol})$ in $300 \mathrm{~mL}$ of dry dichloromethane was carried out in the presence of 0.1 equivalent of TFA as a catalyst under inert atmosphere at room temperature for $1 \mathrm{~h}$. Then, 3 equivalents of DDQ were added to the reaction mixture and stirred in open air for additional $1 \mathrm{~h}$. The TLC analysis of the reaction mixture clearly showed the appearance of minor yellowish spot followed by a major green spot. The solvent was evaporated and the crude compound was subjected to basic column chromatography. The desired oxasmaragdyrins 2-4 were eluted as green band by using petroleum ether/dichloromethane (70:30) and afforded green solid of pure 2-4 in 20-22\% yield.

2.3a Compound 2: Yield 25\% (135 mg); ${ }^{1} \mathrm{H}$ NMR $\left(400 \mathrm{MHz}, \mathrm{CDCl}_{3}, 25^{\circ} \mathrm{C}\right.$ ): $\delta 9.50$ (broad singlet, $1 \mathrm{H}$, $\mathrm{NH}), 9.24(\mathrm{~d}, 2 \mathrm{H}, J(\mathrm{H}, \mathrm{H})=4.04 \mathrm{~Hz}, \beta$-pyrrole $\mathrm{H})$, $9.14(\mathrm{~d}, 2 \mathrm{H}, J(\mathrm{H}, \mathrm{H})=3.92 \mathrm{~Hz}, \beta$-pyrrole $\mathrm{H}), 9.09$ $(\mathrm{d}, 2 \mathrm{H}, J(\mathrm{H}, \mathrm{H})=3.92 \mathrm{~Hz}, \beta$-pyrrole $\mathrm{H}), 8.65(\mathrm{~s}$, $2 \mathrm{H}, \beta$-furan $\mathrm{H}), 8.26(\mathrm{~d}, 2 \mathrm{H}, J(\mathrm{H}, \mathrm{H})=4.00 \mathrm{~Hz}$, $\beta$-pyrrole $\mathrm{H}), 8.04$ (d, 4H, $J(\mathrm{H}, \mathrm{H})=7.45 \mathrm{~Hz}, \mathrm{Ar}), 7.51$ (d, 1H, meso-pyrrole ring), $7.33(\mathrm{~d}, 1 \mathrm{H}, J(\mathrm{H}, \mathrm{H})=2.92$ $\mathrm{Hz}$, meso-pyrrole ring), $\delta 7.06(\mathrm{~d}, 4 \mathrm{H}, J(\mathrm{H}, \mathrm{H})=7.60$ $\mathrm{Hz}, \mathrm{Ar}$ ), 6.80 (dd, 1H, meso-pyrrole ring), 2.80 (s, 6H, $\left.\mathrm{CH}_{3}\right)$ ppm. HR-MS calcd. for $\mathrm{C}_{41} \mathrm{H}_{32} \mathrm{~N}_{5} \mathrm{O}(\mathrm{M}+\mathrm{H})^{+} \mathrm{m} / z$ 610.2601, observed 610.2604.

2.3b Compound 3: Yield 22\% (135 mg); ${ }^{1} \mathrm{H}$ NMR $\left(500 \mathrm{MHz}, \mathrm{CDCl}_{3}, 25^{\circ} \mathrm{C}\right): 9.52(\mathrm{~d}, 2 \mathrm{H}, J(\mathrm{H}, \mathrm{H})=4.25$ $\mathrm{Hz}, \beta$-pyrrole $\mathrm{H}), 9.43(\mathrm{~d}, 2 \mathrm{H}, J(\mathrm{H}, \mathrm{H})=4.25 \mathrm{~Hz}$, $\beta$-pyrrole $\mathrm{H}), 9.27(\mathrm{~d}, 2 \mathrm{H}, J(\mathrm{H}, \mathrm{H})=4.20 \mathrm{~Hz}, \beta$-pyrrole $\mathrm{H}), 8.81(\mathrm{~s}, 2 \mathrm{H}, \beta$-furan $\mathrm{H}), 8.49(\mathrm{~d}, 2 \mathrm{H}, J(\mathrm{H}, \mathrm{H})=4.25$ $\mathrm{Hz}, \beta$-pyrrole $\mathrm{H}), 8.01(\mathrm{~d}, 4 \mathrm{H}, J(\mathrm{H}, \mathrm{H})=7.68 \mathrm{~Hz}, \mathrm{Ar})$, $7.95(\mathrm{~d}, 1 \mathrm{H}, J(\mathrm{H}, \mathrm{H})=3.24 \mathrm{~Hz}$, meso-thiophene ring), $7.61(\mathrm{~d}, 4 \mathrm{H}, J(\mathrm{H}, \mathrm{H})=7.70 \mathrm{~Hz}, \mathrm{Ar}), 7.02(\mathrm{dd}, 1 \mathrm{H}$, $J(\mathrm{H}, \mathrm{H})=3.24 \mathrm{~Hz}$, meso-thiophene ring $), 7.00(\mathrm{~d}, 1 \mathrm{H}$, 
$J(\mathrm{H}, \mathrm{H})=1.64 \mathrm{~Hz}$, meso-thiophene ring), $2.80(\mathrm{~s}, 6 \mathrm{H}$, $\left.\mathrm{CH}_{3}\right)$ ppm. HR-MS calcd. for $\mathrm{C}_{41} \mathrm{H}_{31} \mathrm{~N}_{4} \mathrm{OS}(\mathrm{M}+\mathrm{H})^{+}$ $m / z$ 627.2213, observed 627.2219.

2.3c Compound 4: Yield 20\% (135 mg); ${ }^{1} \mathrm{H}$ NMR $\left(400 \mathrm{MHz}, \mathrm{CDCl}_{3}, 25^{\circ} \mathrm{C}\right): 9.54(\mathrm{~d}, 2 \mathrm{H}, J(\mathrm{H}, \mathrm{H})=4.12$ $\mathrm{Hz}, \beta$-pyrrole $\mathrm{H}), 9.47(\mathrm{~d}, 2 \mathrm{H}, J(\mathrm{H}, \mathrm{H})=4.32 \mathrm{~Hz}$, $\beta$-pyrrole $\mathrm{H}), 9.45(\mathrm{~d}, 2 \mathrm{H}, J(\mathrm{H}, \mathrm{H})=4.28 \mathrm{~Hz}, \beta$-pyrrole $\mathrm{H}), 8.81(\mathrm{~s}, 2 \mathrm{H}, \beta$-furan $\mathrm{H}), 8.51(\mathrm{~d}, 2 \mathrm{H}, J(\mathrm{H}, \mathrm{H})=$ $4.32 \mathrm{~Hz}, \beta$-pyrrole $\mathrm{H}), 8.21(\mathrm{~d}, 1 \mathrm{H}, J(\mathrm{H}, \mathrm{H})=2.50$ $\mathrm{Hz}$, meso-furan ring), $8.01(\mathrm{~d}, 4 \mathrm{H}, J(\mathrm{H}, \mathrm{H})=7.75 \mathrm{~Hz}$, Ar), $7.61(\mathrm{~d}, 4 \mathrm{H}, J(\mathrm{H}, \mathrm{H})=7.76 \mathrm{~Hz}, \mathrm{Ar}), 7.53(\mathrm{~d}, 1 \mathrm{H}$, $J(\mathrm{H}, \mathrm{H})=6.35 \mathrm{~Hz}$, meso-furan ring $), 7.05(\mathrm{dd}, 1 \mathrm{H}, J$ $(\mathrm{H}, \mathrm{H})=5.85 \mathrm{~Hz}$, meso-furan ring $), 2.80\left(\mathrm{~s}, 6 \mathrm{H}, \mathrm{CH}_{3}\right)$ ppm. HR-MS calcd. for $\mathrm{C}_{41} \mathrm{H}_{31} \mathrm{~N}_{4} \mathrm{O}_{2}(\mathrm{M}+\mathrm{H})^{+} \mathrm{m} / \mathrm{z}$ 611.2442, observed 611.2440.

\section{Results and Discussion}

The required precursors, 16-oxatripyrrane $\mathbf{5}$ and the meso-pyrrolyl/thienyl/furyl dipyrromethanes $\mathbf{6 / 7 / 8}$ were prepared by following the reported procedures. ${ }^{9,10}$ The mono-five membered heterocycle containing oxasmaragdyrins 2-4 were prepared by [3+2] acidcatalyzed oxidative coupling reaction of one equivalent of 16-oxatripyrrane 5 with one equivalent of appropriate meso-heterocycle dipyrromethane $\mathbf{6 / 7 / 8}$ in $\mathrm{CH}_{2} \mathrm{Cl}_{2}$ in the presence of 0.1 equivalent of TFA as catalyst for $1 \mathrm{~h}$ under inert atmosphere followed by oxidation with three equivalents of DDQ in open air at room temperature (Scheme 1). The TLC analysis showed the formation of desired oxasmaragdyrin $\mathbf{2 / 3 / 4}$ along with traces of unidentified less polar compound. The crude reaction mixture was subjected to basic alumina column and afforded the pure oxasmaragdyrin $\mathbf{2 / 3 / 4}$ as green solid in $20-25 \%$ yield. The compounds $\mathbf{2}-\mathbf{4}$ were freely soluble in common organic solvents and confirmed their identities by respective molecular ion peak in HR-MS. The compounds $\mathbf{2}-\mathbf{4}$ were characterized in detail by $1 \mathrm{D}$ and 2D NMR spectroscopy.

\subsection{NMR Studies}

The ${ }^{1} \mathrm{H}$ and ${ }^{1} \mathrm{H}-{ }^{1} \mathrm{H}$ COSY NMR spectra of meso-furyl smaragdyrin $\mathbf{4}$ are presented in Figure 1. The compound meso-furyl smaragdyrin 4 showed four sets of doublets at $9.54 \mathrm{ppm}, 9.47 \mathrm{ppm}, 9.45 \mathrm{ppm}, 8.51 \mathrm{ppm}$, for eight $\beta$-pyrrole protons and one singlet at 8.81 ppm for two $\beta$-furan protons. In addition, we observed two sets of doublets at $8.21 \mathrm{ppm}, 7.53 \mathrm{ppm}$, and one doublet of doublet at $7.05 \mathrm{ppm}$ for the three protons

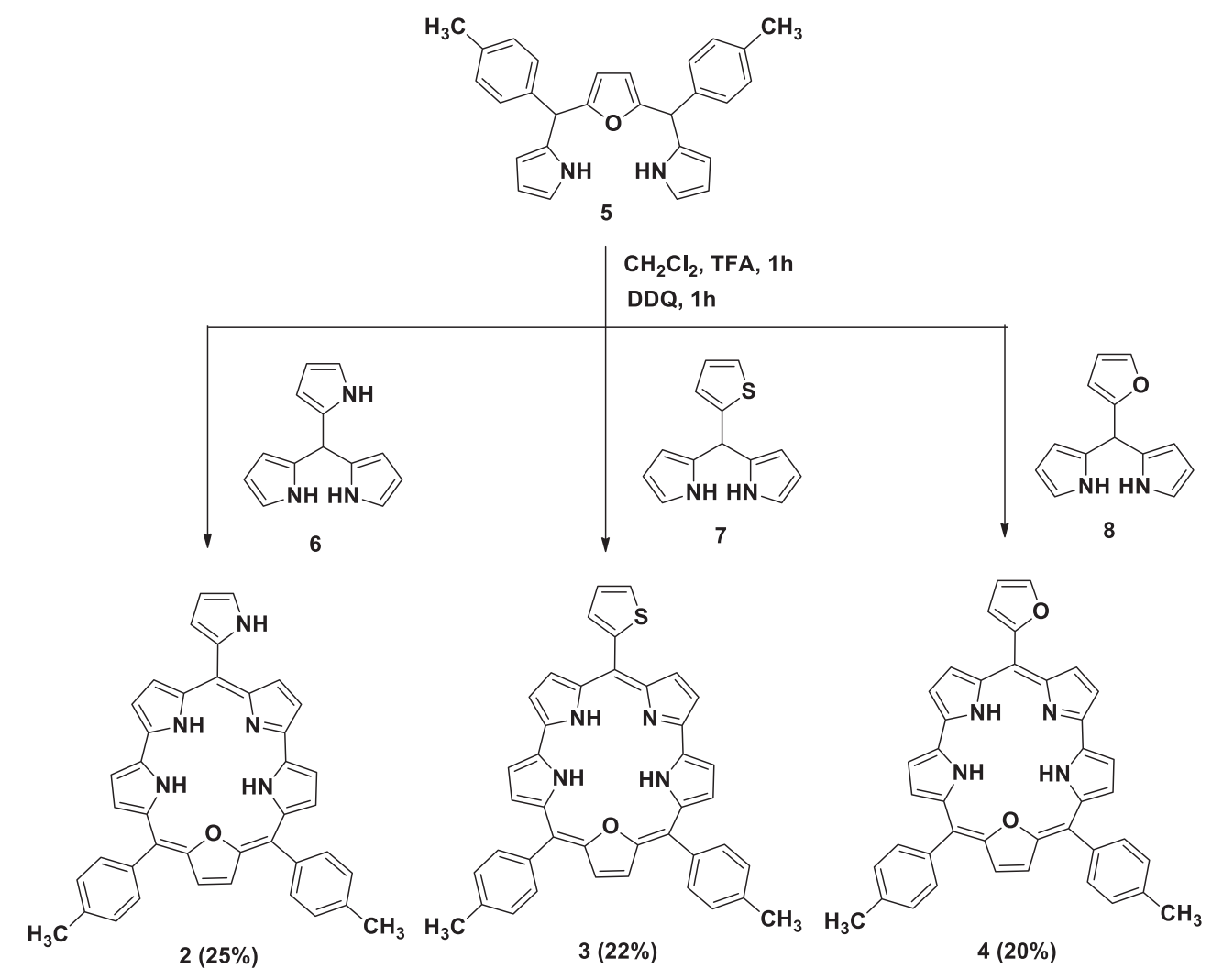

Scheme 1. Synthesis of various oxasmaragdyrins 2-4 having different meso-heterocyclic group. 
corresponding to the meso-furyl rings and a singlet at $2.80 \mathrm{ppm}$ for six meso-tolyl protons (Figure 2). The singlet resonance appearing at $8.81 \mathrm{ppm}$ was assigned to type a protons of $\beta$-furan protons. It is clear from the the ${ }^{1} \mathrm{H}-{ }^{1} \mathrm{H}$ COSY spectrum of compound 4 presented in Figure $1 \mathrm{~b}$ that the doublet at $9.47 \mathrm{ppm}$ showed crosspeak connectivity with doublet at $9.45 \mathrm{ppm}$ whereas the doublet at $9.54 \mathrm{ppm}$ with $8.51 \mathrm{ppm}$ (Figure 1). Thus, we assigned the peak at $9.47 \mathrm{ppm}$ as type $c$ proton and peak at $9.45 \mathrm{ppm}$ as type $b$ proton. Similarly, from correlation we have assigned peaks at $8.51 \mathrm{ppm}$ and $9.51 \mathrm{ppm}$ as type $d$ and $e$ - protons, respectively. ${ }^{6}$ The three protons of meso-furyl group (types $f, g, h$ protons) showed correlation among themselves and thus assigned peaks at $7.53 \mathrm{ppm}, 7.05 \mathrm{ppm}$ and $8.21 \mathrm{ppm}$ as types $f, g, h$ protons, respectively. Similarly, compounds $\mathbf{2}$ and 3 also exhibited identical pattern of ${ }^{1} \mathrm{H}$ NMR resonances and the resonances were assigned based on 1D and 2D NMR studies (Table 1). Thus, 1D and 2D NMR were very useful in deducing the molecular structures of meso-heterocycle substituted oxasmaragdyrins 2-4.

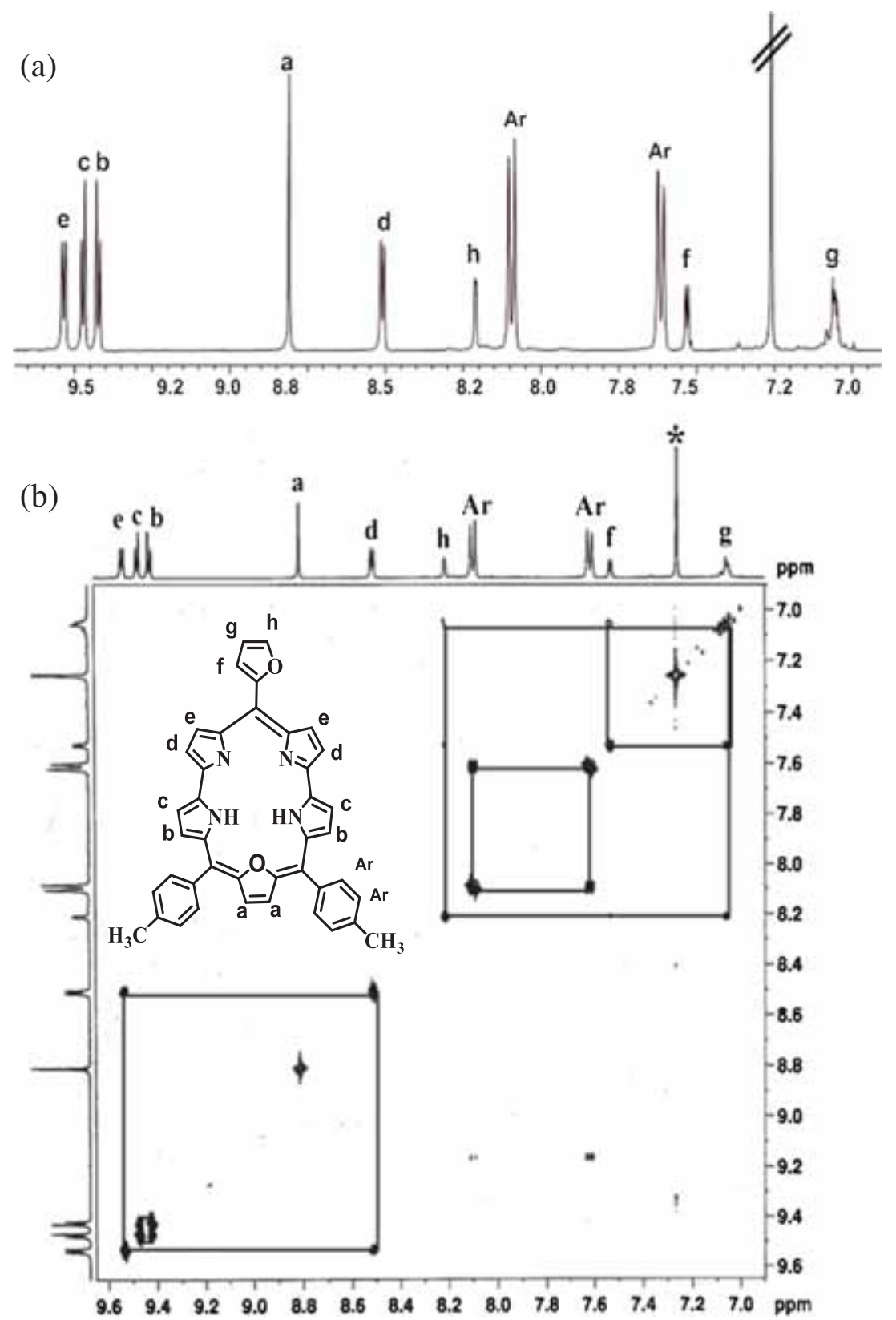

Figure 1. (a) ${ }^{1} \mathrm{H}$ NMR and (b) ${ }^{1} \mathrm{H}_{-}{ }^{1} \mathrm{H}$ COSY NMR spectrum of compound 4 recorded in $\mathrm{CDCl}_{3}$ at room temperature. The double crossed peak in (a) and an asterix marked peak in (b) correspond to $\mathrm{CDCl}_{3}$. 


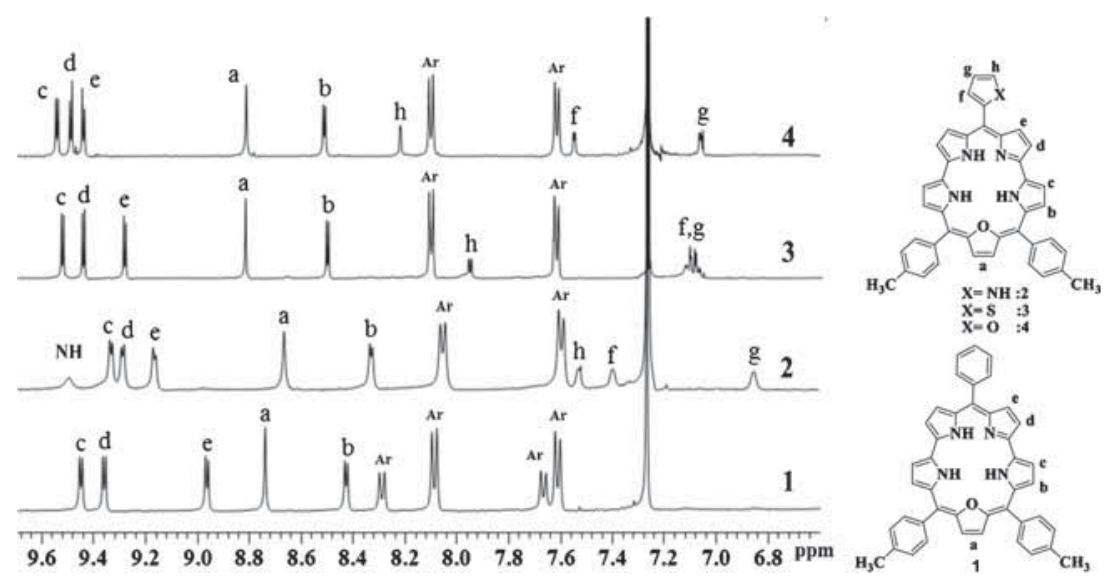

Figure 2. Comparison of a selected region of ${ }^{1} \mathrm{H}$ NMR spectra of compounds $\mathbf{2 , 3}, \mathbf{4}$ and $\mathbf{1}$ recorded in $\mathrm{CDCl}_{3}$ at room temperature.

Table 1. ${ }^{1} \mathrm{H}$ NMR data ( $\delta$ in $\mathrm{ppm}$ ) of meso-heterocycle oxasmaragdyrins $\mathbf{2 - 4}$ along with oxasmaragdyrin $\mathbf{1}$ recorded in $\mathrm{CDCl}_{3}$.

\begin{tabular}{|c|c|c|c|c|c|c|c|c|}
\hline \multirow[b]{2}{*}{ Comp } & \multicolumn{2}{|c|}{$\beta$-furan } & \multicolumn{3}{|c|}{$\beta$-pyrrole } & \multicolumn{3}{|c|}{ Heterocyclic ring } \\
\hline & $\mathbf{H}_{\mathbf{a}}$ & $\mathbf{H}_{b}$ & $\mathbf{H}_{\mathbf{c}}$ & $\mathbf{H}_{\mathrm{d}}$ & $\mathbf{H}_{\mathrm{e}}$ & $\mathbf{H}_{\mathrm{f}}$ & $\mathbf{H}_{\mathrm{g}}$ & $\mathbf{H}_{\mathrm{h}}$ \\
\hline 1 & $8.72(\mathrm{~s})$ & $8.44(d)$ & $9.49(\mathrm{~d})$ & $9.38(\mathrm{~d})$ & $8.96(d)$ & - & - & - \\
\hline 2 & $8.65(\mathrm{~s})$ & $8.26(d)$ & $9.24(\mathrm{~d})$ & $9.14(d)$ & $9.09(\mathrm{~d})$ & $7.33(\mathrm{~d})$ & $6.80(\mathrm{dd})$ & $7.51(\mathrm{~d})$ \\
\hline 3 & $8.81(\mathrm{~s})$ & $9.27(\mathrm{~d})$ & $9.43(d)$ & $8.49(\mathrm{~d})$ & $9.52(\mathrm{~d})$ & $7.00(\mathrm{~d})$ & $7.02(\mathrm{dd})$ & $7.95(\mathrm{~d})$ \\
\hline 4 & $8.81(\mathrm{~s})$ & $9.45(\mathrm{~d})$ & $9.47(\mathrm{~d})$ & $8.51(\mathrm{~d})$ & $9.54(\mathrm{~d})$ & $7.53(\mathrm{~d})$ & $7.05(\mathrm{dd})$ & $8.21(\mathrm{~d})$ \\
\hline
\end{tabular}

The effect of six membered phenyl groups versus five membered pyrroryl/thienyl and furyl groups is clearly reflected in the ${ }^{1} \mathrm{H}$ NMR spectra of the compounds 1-4. The comparison of selected region of ${ }^{1} \mathrm{H}$ NMR spectra of compounds $\mathbf{2}, \mathbf{3}$ and $\mathbf{4}$ along with the mesotriaryl-oxasmaragdyrin $\mathbf{1}$ is presented in Figure 2. In all the four compounds $\mathbf{1 - 4}$, the eight $\beta$-pyrrole protons of smaragdyrin macrocycle appeared as four doublets and two $\beta$-furan protons appeared as one singlet. It is clear from the Figure 2 that the $\beta$-pyrrole and $\beta$-furyl protons of compounds 2-4 experienced downfield shifts compared to compound $\mathbf{1}$. This supports the alteration in the ring current of smaragdyrin macrocycle upon changing the meso-substituent from six membered phenyl group to five membered pyrroyl/thienyl and furyl groups.

\subsection{Spectral and Electrochemical Properties}

The absorption, fluorescence and electrochemical properties of meso-heterocycle substituted oxasmaragdyrins 2, 3 and $\mathbf{4}$ were studied along with oxasmaragdyrin $\mathbf{1 .}$ The comparison of absorption spectra of compounds 1-4 is presented in Figure $3 a$ and the data are presented in Table 2. The compound $\mathbf{1}$ exhibited one Soret band at $443 \mathrm{~nm}$ with a shoulder at $456 \mathrm{~nm}$ and four well defined Q-bands at 552, 592, 633 and $696 \mathrm{~nm} .{ }^{5}$ Similarly, the compound $\mathbf{4}$ also showed one Soret band at $451 \mathrm{~nm}$ with a shoulder at $472 \mathrm{~nm}$ and four Q-bands at $564 \mathrm{~nm}, 607 \mathrm{~nm}, 651 \mathrm{~nm}$ and $716 \mathrm{~nm}$. Thus, the introduction of five membered heterocycle such as pyrrole/thiophene/furan at the meso position of oxasmaragdyrin 2-4 in place of six membered aryl groups showed similar absorption features with 8-10 nm bathochromic shifts in their absorption maxima. Furthermore, the maximum red shifts in absorption bands were observed for compound 4 . We also recorded the absorption spectra of protonated oxasmaragdyrins $\mathbf{1} \mathbf{H}^{+}-\mathbf{4} \mathbf{H}^{+}$and the comparison of absorption spectra of $\mathbf{1} \mathbf{H}^{+}$and $\mathbf{4} \mathbf{H}^{+}$is shown in Figure 3b. Upon addition of excess (20 equiv.) amounts of TFA to $\mathbf{1}$ in $\mathrm{CHCl}_{3}$, the Soret band shifted to $449 \mathrm{~nm}$ with an appearance of another new band at $482 \mathrm{~nm}$ because of generation of $\mathbf{1} \mathbf{H}^{+}$. All the Q-bands were also shifted bathochromically and the last Q-band appeared at 722 $\mathrm{nm}$ in $\mathbf{1} \mathbf{H}^{+}$. Similarly, the compounds $\mathbf{2 - \mathbf { 4 }}$ also showed bathochromic shifts in both Soret and Q-bands upon protonation (Table 2). 
Table 2. Absorption and emission data for compounds 1-4 along with their protonated species.

\begin{tabular}{lcccc}
\hline Comp & $\begin{array}{c}\text { Soret bands, } \lambda_{\text {abs }} / \mathrm{nm} \\
\left(\log \varepsilon / \mathrm{M}^{-1} \mathrm{~cm}^{-1}\right)\end{array}$ & Q-bands, $\lambda_{\text {abs }} / \mathrm{nm}\left(\log \varepsilon / \mathrm{M}^{-1} \mathrm{~cm}^{-1}\right)$ & $\lambda_{\mathrm{em}} / \mathrm{nm}$ & $\Phi_{\mathrm{f}}$ \\
\hline $\mathbf{1}$ & $444(5.8), 456(\mathrm{sh})$ & $552(4.4), 592(3.9), 633(3.6), 696(4.0)$ & 703 & 0.148 \\
$\mathbf{1 . H}$ & 449,482 & $604,658,722$ & - & - \\
$\mathbf{2}$ & $453(5.6), 469(\mathrm{sh})$ & $562(3.8), 600(3.9), 642(3.6), 706(4.2)$ & 716 & 0.142 \\
$\mathbf{2 . H}$ & 459,495 & $604,652,721$ & - & - \\
$\mathbf{3}$ & $454(5.4), 472(\mathrm{sh})$ & $566(3.9), 604(3.7), 652(3.8), 721(4.2)$ & 721 & 0.088 \\
$\mathbf{3 . H}$ & 456,494 & $609,675,740$ & - & - \\
$\mathbf{4}$ & $452(5.4), 465(\mathrm{sh})$ & $563(3.9), 605(3.8), 651(3.6), 717(4.5)$ & 728 & 0.091 \\
$\mathbf{4 . H}$ & 455,494 & $615,674,744$ & - & - \\
\hline
\end{tabular}

(a)

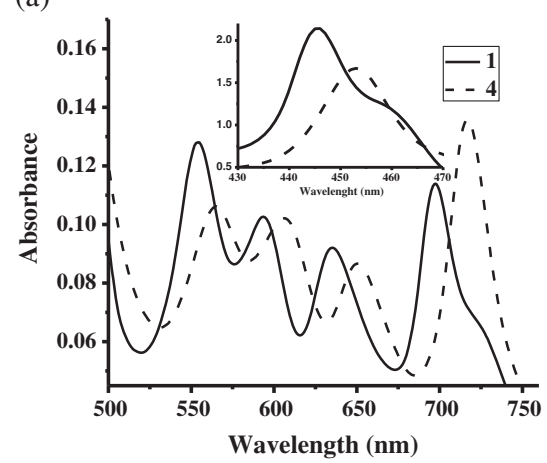

(c)

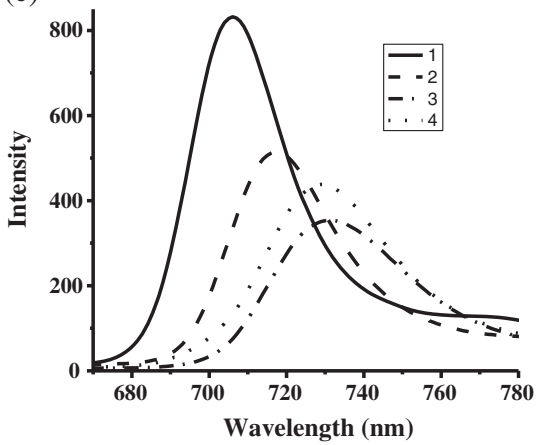

(b)

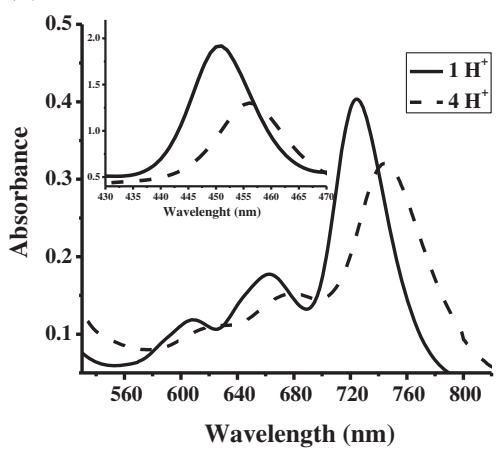

(d)

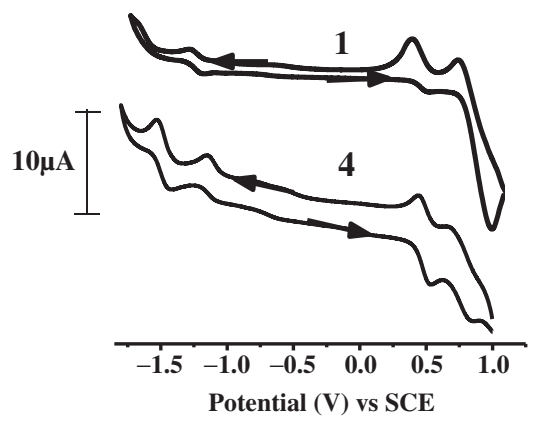

Figure 3. Comparison of $\mathrm{Q}$ and Soret band absorption spectra of compounds: (a) $\mathbf{1}$ and $\mathbf{4}$, and (b) $\mathbf{1} \mathbf{H}^{+}$and $\mathbf{4} \mathbf{H}^{+}$recorded in $\mathrm{CHCl}_{3}$. The concentrations used were $10^{-5}$ and $10^{-6} \mathrm{M}$ for the $\mathrm{Q}$ and Soret bands, respectively. The compounds $\mathbf{1 H}^{+}$and $\mathbf{4} \mathbf{H}^{+}$were generated by addition of a drop of trifluoroacetic acid to 1 and 4, respectively, in $\mathrm{CHCl}_{3}$. (c) Comparison of steady state fluorescence spectra of compounds 1-4 $\left(1 \times 10^{-6} \mathrm{M}\right)$ recorded in $\mathrm{CHCl}_{3}$ at room temperature. (d) Comparison of cyclic voltammograms of compounds 1 and $4(1 \times$ $10^{-3} \mathrm{M}$ ) recorded in dichloromethane containing $0.1 \mathrm{M}$ tetrabutylammonium perchlorate as the supporting electrolyte recorded at $50 \mathrm{mV} \mathrm{s}^{-1}$ scan rate.

The steady state fluorescence spectra of oxasmaragdyrins 1-4 recorded in $\mathrm{CHCl}_{3}$ are presented in Figure 3c. The compound $\mathbf{1}$ is decently fluorescent and exhibits one band around $703 \mathrm{~nm}$. The meso-heterocycle substituted oxasmaragdyrins $2-\mathbf{4}$ also exhibited one fluorescence band which was shifted bathochromically by $15-25 \mathrm{~nm}$ compared to compound 1. However, the meso-heterocycle substituted oxasmaragdyrins 2-4 are relatively less fluorescent and the quantum yield of compound $\mathbf{3}$ is less compared to compounds 2 and 4 . Thus, the absorption and emission studies supported the alteration of electronic properties of the oxasmaragdyrin macrocycle on changing six membered phenyl group with five membered pyrroyl, thienyl and furyl groups at one of the mesopositions. These effects are attributed to the orientation of meso-substituent with respect to the macrocyclic skeleton. The five membered meso-heterocyclic group 
Table 3. Electrochemical redox data (V) of oxasmaragdyrins 1-4 recorded in dichloromethane containing $0.1 \mathrm{M}$ TBAP as supporting electrolyte using scan rate of 50 $\mathrm{mV} / \mathrm{sec}$. $\mathrm{E}_{1 / 2}$ values reported are relative to $\mathrm{SCE}$.

\begin{tabular}{lcccc}
\hline Compound & $\begin{array}{c}\mathrm{I} \\
\mathrm{E}_{\mathrm{ox}}(\mathrm{V})\end{array}$ & $\begin{array}{c}\mathrm{II} \\
\mathrm{E}_{\mathrm{Ox}}(\mathrm{V})\end{array}$ & $\begin{array}{c}\mathrm{I} \\
\mathrm{E}_{\mathrm{red}}(\mathrm{V})\end{array}$ & $\begin{array}{c}\mathrm{II} \\
\mathrm{E}_{\mathrm{red}}(\mathrm{V})\end{array}$ \\
\hline $\mathbf{1}$ & 0.54 & 0.97 & -1.28 & - \\
$\mathbf{2}$ & 0.55 & 0.79 & -1.18 & -1.56 \\
$\mathbf{3}$ & 0.53 & 0.80 & -1.16 & -1.50 \\
$\mathbf{4}$ & 0.54 & 0.84 & -1.14 & -1.47 \\
\hline
\end{tabular}

in compounds $\mathbf{2 - 4}$ is expected to be more in-plane arrangement with the smaragdyrin ring resulting in efficient extension of the macrocyclic $\pi$-conjugation into meso-substitutent.

The electrochemical properties of oxasmaragdyrins 1-4 were investigated using cyclic voltammetry $(\mathrm{CV})$ in dichloromethane with tetrabutylammonium perchlorate as supporting electrolyte. A comparison of cyclic voltammograms of oxasmaragdyrin $\mathbf{4}$ and smaragdyrin $\mathbf{1}$ is shown in Figure 3d and the data for compounds 1-4 is presented in Table 3. The compound $\mathbf{1}$ smaragdyrin exhibits two oxidations at 0.54 and $0.97 \mathrm{~V}$ and one reduction at $-1.28 \mathrm{~V}$. The meso-heterocycle substituted smaragdyrins 2-4 also showed two reversible oxidations, one reversible reduction and one irreversible reduction. However, the oxidation potentials of meso-heterocycle substituted smaragdyrins 2-4 were shifted towards more positive with slight decrease in their reduction potentials compared to compound $\mathbf{1}$ indicating that the introduction of five-membered heterocycle in place of six membered phenyl ring makes the resulted smaragdyrin macrocycles 2-4 more electron deficient than compound $\mathbf{1}$.

\section{Conclusions}

We synthesized mono-meso-pyrroyl/thienyl/furyl substituted oxasmaragdyrin in decent yields by adopting TFA catalyzed $3+2$ acid-catalyzed oxidative coupling reaction method. The effect of five membered heterocycle such as pyrrolyl/thienyl/furyl group in place of one six membered aryl group at one of the mesoposition was clearly reflected in spectral and electrochemical properties. The absorption and emission spectra of meso-five membered heterocycle containing smaragdyrin macrocycle showed bathochromic shifts and maximum effects were observed for meso-furyl oxasmaragdyrin compared to meso-aryl smaragdyrin. The electrochemical studies indicated that the five membered meso-substituted smaragdyrins are difficult to oxidize compared to six membered meso-aryl smaragdyrin. Thus, the electronic and structural features of oxasmaragdyrin macrocycle can be fine tuned by changing the meso-substituents from six membered aryl group to five membered heterocycle. The presence of five membered heterocycle at one of the mesopositions is also very useful precursor to prepare novel fluorescent systems and such synthetic efforts are currently underway in our laboratory.

\section{Acknowledgements}

We thank Department of Science and Technology, Govt. of India for funding the project. US thanks UGC for JRF fellowship.

\section{Supplementary Information (SI)}

Supplementary data (mass spectra and NMR spectra) associated with the article are available at www.ias.ac. in/chemsci.

\section{References}

1. (a) Pareek Y, Ravikanth M and Chandrashekar T K 2012 Acc. Chem. Res. 45 1801; (b) Sridevi B, Narayanan S J and Chandrashekar T K 2000 J. Chem. Sci. 112422

2. (a) Woodward R B 1966 In Aromaticity: An International Symposium Sheffield Special Publication no. 21 (London: The Chemical Society); (b) Broadhurst M J, Grigg R and Johnson A W 1972 J. Chem. Soc., Perkin Trans. 12111

3. Bauer V J, Clive D L J, Dolphin D, Paine J B, Harris F L, King M M, Loder J, Wang S W C and Woodward R B 1983 J. Am. Chem. Soc. 1056429

4. Sessler J L, Camiolo S and Gale P A 2003 Coordin. Chem. Rev. 24017

5. Narayanan S J, Sridevi B and Chandrashekar T K 1999 Org. Lett. 4587

6. Sridevi B, Narayanan S J, Rao R and Chandrashekar T K 2000 Inorg. Chem. 393669

7. Rajeswara R M and Ravikanth M 2011 J. Org. Chem. 76 3582

8. Kalita H, Lee W Z and Ravikanth M 2014 Inorg. Chem. 539431

9. Ulman A and Manassen J 1975 J. Am. Chem. Soc. 97 6540

10. Gross Z, Saltsman I, Pandian R P and Barzilay C 1997 Tetrahedron Lett. 382383 